\title{
Performance evaluation of fiber-based ballistic composites against laser threats
}

\author{
Can Candan ${ }^{\mathrm{a}}$, A. Aytaç Seymen ${ }^{\mathrm{b}, \mathrm{c}}$, Ali Karatutlu ${ }^{\mathrm{b}}$, Mehmet Tiken ${ }^{\mathrm{a}, \mathrm{d}}$, Yakup Midilli ${ }^{\mathrm{b}}$, Elif Orhan ${ }^{\mathrm{e}}$, \\ Halil Berberoğlu ${ }^{\mathrm{f}}$, Bülend Ortaç ${ }^{\mathrm{b}, *}$
}

a 5th Main Maintenance Factory Directorate, Avionic Department, Ankara 06990, Turkey

${ }^{\mathrm{b}}$ UNAM - National Nanotechnology Research Center and Institute of Materials Science and Nanotechnology, Bilkent University, Ankara 06800, Turkey

${ }^{\mathrm{c}}$ E-A Teknoloji LLC, Ankara 06800, Turkey

${ }^{\mathrm{d}}$ Graduate School of Natural and Applied Science, Department of Advanced Technology, Gazi University, Ankara 06500, Turkey

e Science Faculty, Physics Department, Gazi University, Ankara 06500, Turkey

${ }^{\mathrm{f}}$ Polatli Art and Science Faculty, Physics Department, Ankara Hacı Bayram Veli University, Ankara 06900, Turkey

\section{A R T I C L E I N F O}

\section{Keywords:}

Laser

Directed beam

Ballistic

Composite

Polyethylene

\begin{abstract}
A B S T R A C T
The interaction between a laser and a composite material has been an intense subject within the past decade and become an emerging field for the defense and manufacturing industry since high-power lasers were initiated to be utilized for the directed-beam applications. In this study, a specially developed composite material for the ballistic applications was shined to a continuous wave (CW) laser beam at $915 \mathrm{~nm}$. The ballistic material was composed of 77 layers of the single sheet of the SR-3136 by Spectra Shield ${ }^{\circledR}$ from Honeywell consisting of ultra-high molecular weight polyethylene (UHMW-PE) fibers reinforced with low-density PE (LD-PE) fibers and a polyurethane-based thermoplastic resin. At the instant of the exposure, the region of interest was completely evaporated and punctured with a slight swelling around the hole where the temperature was over $450{ }^{\circ} \mathrm{C}$. The composite material was drilled completely upon exceeding $20 \mathrm{~kJ}$ of laser energy. The chemical and physical changes on the composite material after the laser exposure were extensively studied by a combination of techniques including High-Resolution Scanning Electron Microscopy (HR-SEM), Energy Dispersive X-ray Spectroscopy (EDX) and X-ray Photoelectron Spectroscopy (XPS). The physical properties of a single layer of the SR-3136 were also studied using HR-SEM, UVVIS-NIR Absorption Spectroscopy, Thermogravimetric analysis (TGA), Differential Scanning Calorimetry (DSC) and XPS. The research presented here reveals the first study on the effects of the high-power laser beam irradiance on the fiber-reinforced composite materials utilized for the ballistic protection.
\end{abstract}

\section{Introduction}

Composite materials are utilized as ballistic protective materials which are inevitable for personal and vehicle protection against the treats in the battlefields where all kinds of weapons are used. The most important demand in this context is the high strength and high modulus against ballistic impact and the lightweight. Besides, it is expected to ensure wear comfort, good flexibility, and property stability under various conditions [1]. Fiber-based ballistic composites are promising candidates for the various type of applications due to their intrinsic advantages. The mechanical properties of the fiber become crucial when the fabric undergoes ballistic impact. Fiber-based composites such as aramid fibers and UHMW-PE stand out in this regard and they still remain the major materials in ballistic body composites despite the continuing efforts to make new and better fibers for ballistic protection. Since high strength and high modulus material offer the best performance-to- weight ratios, UHMW-PE fibers, with their combination of high strength and low-density properties are one of the strongest and lightest fibers available [2]. High-performance fibers with compatible resins can make a good combination to prevent attacks. In general, UHMW-PE fiber composites can be used as in bullet-resistant protective vests and helmets, and vehicle protection as well. Conventional kinetic weapons such as bullets make an impact on the target that is relatively well understood. Bullet hits the target with a given kinetic energy and makes damage such as a backface deformation depending on its energy [3].

Directed laser weapons come forward among over the conventional weapons. For instance, it can work non-stop at the cost of only electricity and have a higher probability of hits on target than some other conventional systems [4]. For these reasons, laser weapons would be one of the salient solutions to the growing problem of using expensive weapons in the defense industry. When the material is heated enough by the laser, it starts to meltdown, vaporize and finally disappear through evaporation.

\footnotetext{
* Corresponding author.

E-mail address: ortac@unam.bilkent.edu.tr (B. Ortaç).
} 
Laser and composite material interaction has been important for fundamental science $[4,5]$ as well as for material processing [6] and the manufacturing industry [7]. From the fundamental perspective of the laser \& carbon-based composites interaction, the laser beam can be considered to be transmitted from the surface to intermediate region via several absorption \& scattering events. For instance, polyethylene $\left(\mathrm{C}_{2} \mathrm{H}_{4}\right)_{n}$ generally used within ballistic composites can be absorptive from visible to NIR regions despite the fact that film preparation also plays role in the changes of its refractive index [8]. On the other hand, an extremely high laser power density of $1 \mathrm{~kW} / \mathrm{cm}^{2}$ can cause the carbon-based composite materials to be burned completely where the local temperature could be as high as $3250{ }^{\circ} \mathrm{C}$ [9]. Therefore, lasers can be considered as a heat source in the $\mathrm{CW}$ regime that can be an effective tool when composite materials are considered to be the target.

The laser interaction with different types of composite materials including ceramics $[10]$, metallic glass $[11]$, polymers $[10,12]$ and microfibers [13] was studied, however, to our knowledge, there is no study showing the impacts of a high-power laser on a conventional ballistic composite material. In this study, particularly, with the advent of high-power diode lasers, it would be worth to test the resistance and response of conventional ballistic body armors against laser weapons. The protection capability of the composite material of SR-3136 against the laser threats was evaluated and observed to be ineffective in its current form at the operation wavelength of $915 \mathrm{~nm}$.

\section{Materials and methods}

\subsection{Material preparation}

For this study, Spectra Shield SR-3136 (Honeywell Specialty Materials) was selected to understand its strength to the laser light by comparing to the ballistic strength. The SR-3136 of Spectra Shield is a thermoplastic composite consisting of highly crystalline UHMW-PE fibers that were reinforced by the LD-PE. The single layer was made up four unidirectional layers of UHMW-PE fibers in a cross-ply $\left[0^{\circ} / 90^{\circ} / 0^{\circ} / 90^{\circ}\right]$ layup with a Polyurethane-based thermoplastic resin to reduce the damage during production [14].

In recent years, in the fields of composites ballistic armor manufacturing technologies, two basic materials come to the forefront in order to counteract the treat of the weapons with solid projectiles (bullets), namely para-aramid and UHMW-PE. With the usage of such materials in the manufacturing processes, following critical properties have been obtained: lightness, corrosion resistant, superior ballistic performance, high-energy damping, low thermal conductivity, low internal deformation, high strength against crack spreading, high strength properties against chemicals and corrosion. Physical properties of the SR-3136 is given in the supplementary in Table S1. For this experiment, the SR3136 (Honeywell's patented Spectra fiber) composite structures were fabricated to form a protective ballistic armor against treats (Fig. 1).

After the sheet is ready to form with the desired area and thickness, then it is consolidated and pressed using heated platens. The production of our ballistic armor plate was outlined as follow: First, the SR-3136 was rolled out to the desired shape, thickness and area $(250 \times 300 \mathrm{~mm})$ and consolidated into flat platens. Second, the stacked layer was loaded into the heated platens to be pressed. Finally, the temperature of the platens was set to the desired forming temperature of $120-130{ }^{\circ} \mathrm{C}$ and then pressed 30 min under the 200 bar pressure. It must be noted that the composite must be evenly heated. After that processing, the final plate has had $22.2 \mathrm{~mm}$ thickness (corresponding to 77 layers) and $1450 \mathrm{~g}$ of weight.

\subsection{Characterization}

The material morphological structure was studied using the HighResolution Scanning Electron Microscopy (HR-SEM, Model: FEI Quanta 200 FEG) technique at an accelerating potential difference of $2.0 \mathrm{kV}$ initially on a single sheet of the SR-3136 specimen. The UV-VIS-NIR transmission measurement was taken using Carry 100 Bio UV-Vis Spectrometer from $200 \mathrm{~nm}$ to $3000 \mathrm{~nm}$ with a step of $1 \mathrm{~nm}$ and double-beam configuration. A single sheet of the SR-3136 with a thickness of $0.36 \mathrm{~mm}$ was used in order to estimate the UV-VIS-NIR transmission capability of the SR-3136 having 77 layers. The single sheet of the SR-3136 was further characterized using Thermogravimetric Analysis (TGA), Differential Scanning Calorimetry (DSC) and X-ray Photoelectron Spectroscopy (XPS) techniques. The TGA measurement was utilized by TA Instruments Q500 with a heating rate of $10{ }^{\circ} \mathrm{C}$ from $25{ }^{\circ} \mathrm{C}$ to $1000{ }^{\circ} \mathrm{C}$ under a nitrogen flow of $50 \mathrm{ml} / \mathrm{min}$. Thermo, USA (K $\alpha$-monochromated high performance) in an ultra-high vacuum (UHV) with a conventional X-ray source $(\mathrm{Mg}-\mathrm{K} \alpha)$ was conducted for the XPS technique. C $1 \mathrm{~s}(284.8 \mathrm{eV})$ level was used for the charge-shift correction after collecting the XPS measurements. Energy dispersive X-ray spectroscopy technique within the SEM instrument was used to determine the local elemental analyses in a relevant area.

\subsection{Ballistic tests}

For the ballistic test, the test bench was configured as in Fig. 2. To measure the velocity of the projectile, Model ORM 55 type velocimetry (Oehler Research) was used. Before the ballistic test, the armor plate was conditioned at $23 \pm 2{ }^{\circ} \mathrm{C}$ for $24 \mathrm{~h}$ at $50 \%$ of relative humidity. The projectiles were fired perpendicular to the target plane from a 15-meter distance and each shot is $50 \mathrm{~mm}$ away from the edges. The properties and the image of the projectile $(7.62 \times 51 \mathrm{~mm} \mathrm{G}-3)$ used in this experiment are given in Table S3 and Figure S4 respectively.

\subsection{Laser setup}

The laser used in this experiment is a fiber-coupled diode laser with passive cooling. The fiber coupled laser module with $105 \mu \mathrm{m}$ core size and $915 \mathrm{~nm}$ wavelength was used in the setup. Having a $60 \mathrm{~mm}$ focal length aspheric condenser lens and an $800 \mathrm{~mm}$ focal length planoconvex condenser lens were placed in the system. The simulations on Zemax were found to support the optical configuration utilized in the field studies. The diode supplied by $24 \mathrm{~V}$ and $40 \mathrm{~A}$ was cooled with Peltier cooling and an aluminum block was used as a heat sink. Laser
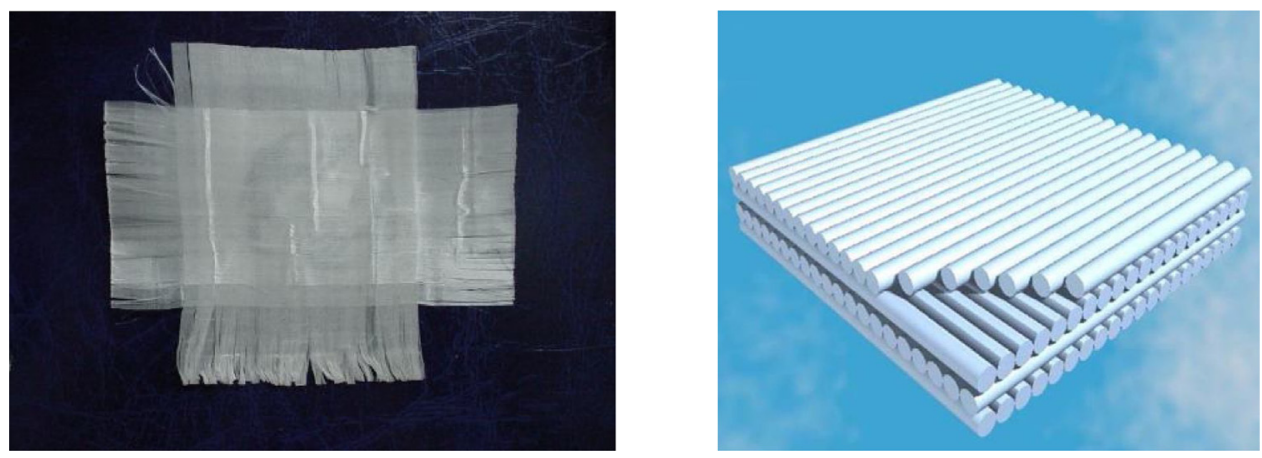

Fig. 1. Schematic representation of the unidirectional fiber sheet for the stiff application. 


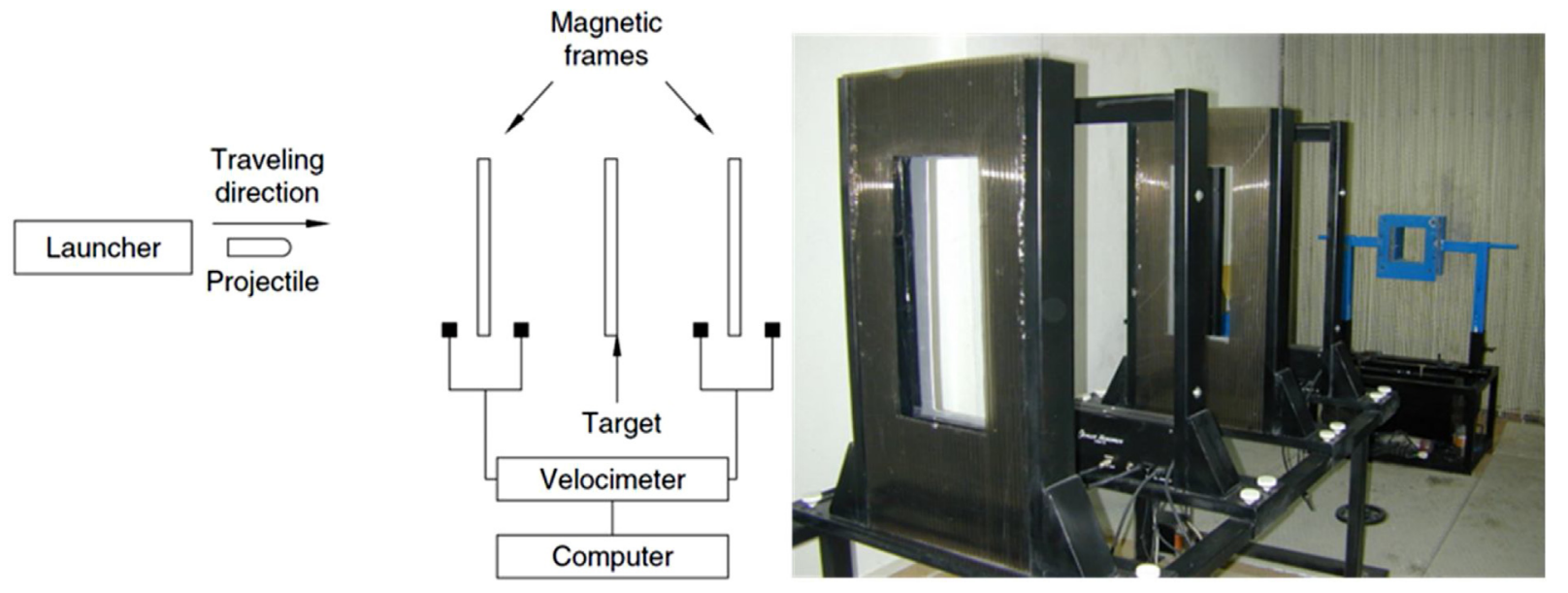

Fig. 2. The schematic representation of the ballistic test.

driver constructed by EA Technology LLC was integrated into the system.

\section{Results and discussions}

\subsection{Material physical properties}

The specimen surface is demonstrated in Figure S1 where the bundles of the UHMW-PE fibers were horizontally designed to be formed one after another. The mean fiber diameter was estimated to be $3.8 \pm 1.0 \mu \mathrm{m}$ in size out of 50 fibers. The fibers in the single sheet appear to be bent quite easy as such deformations were revealed possible even in the SEM sample preparation (see the inset of the Figure S1). Therefore, a single sheet itself can be interpreted to be not a sufficient specimen for the ballistic applications and further improvements such as consolidation was proposed by the hybrid design and the lamination $[2,15]$. The elemental analysis of the single sheet of the SR-3136 was performed using energy dispersive X-ray spectroscopy (EDX). The EDX analysis shows that $89.3 \%$ of $\mathrm{C}$ and $10.7 \%$ of $\mathrm{O}$ are present.

The optical band gap calculations of the SR-3136 were done by Tauc's model [16] using the absorption data calculated from Fig. 3A. The energy levels from the highest occupied molecular orbital (HOMO) to the lowest unoccupied molecular orbital (LUMO) were found for the direct and indirect transitions. These energy levels were determined to be $2 \mathrm{meV}$ and $0.39 \mathrm{eV}$ respectively. On the other hand, the sample appears to absorb most of the incident light in the NIR. The absorption reaches to 99.1 percent at $915 \mathrm{~nm}$ corresponding to the emission wavelength of the diode laser used in this study. Therefore, considering the BeerLambert law, the subsequent 77 layers present in the SR-3136 would ultimately suppress such minute transmitted light. The UV-Vis-NIR transmission measurements also appear to be consistent with the previous results predicting the absorption length at $915 \mathrm{~nm}$ would be much less than the radius of the $C$ fibers [5]. Here, the absorption length, $l_{a}$ of the UHMW-PE and LD-PE fibers can be estimated using Eq. (1) based on the assumption the UHMW-PE and LD-PE fibers have a close refractive index at the operating wavelength of $915 \mathrm{~nm}$ [8] despite the fact that their responses to the ambient temperature changes are different.

$l_{a}=\frac{\lambda}{2 \pi k_{c}}$

Where $\lambda$ and $k_{c}$ are the wavelength and imaginary part of the refractive index respectively. The imaginary part of the refractive index was interpolated from [8] and approximately found to be 2.18 . Thus, the absorption length was estimated to be $0.067 \mu \mathrm{m}$ that is indeed much smaller than the mean fiber diameter of $3.8 \pm 1.0 \mu \mathrm{m}$ determined by the HR-SEM.

The TGA technique was used to determine the temperatures where the sample is fully dissociated. Fig. 3B shows that three different portions of the sample were removed including the additives used for blending of UHMW-PE and LD-PE and the polyethylene chains present in both UHMW-PE and LD-PE. This means that the onset temperatures of $323.5^{\circ} \mathrm{C}$ and $428.7^{\circ} \mathrm{C}$ are considered to stand for the additives and the

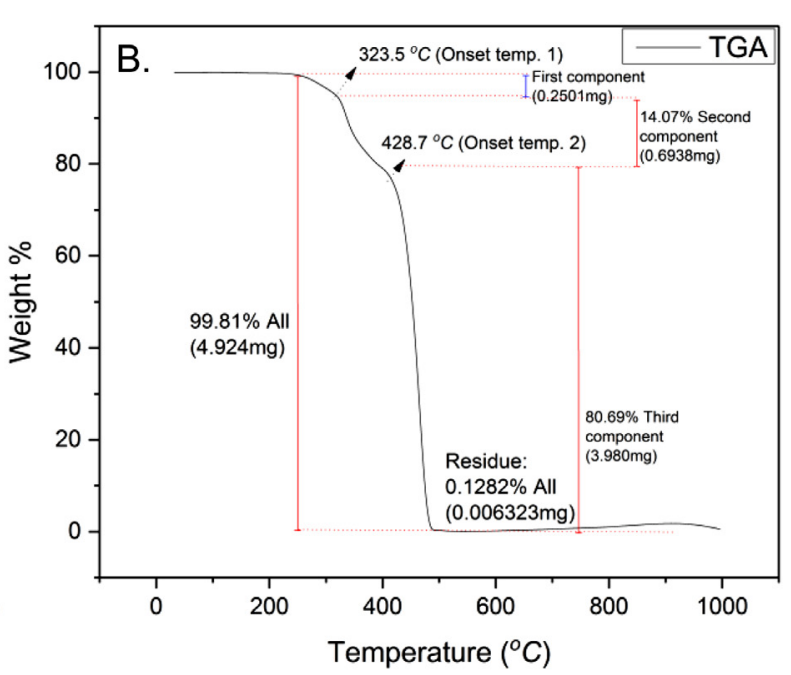

Fig. 3. A. The UV-VIS-NIR Transmission study and B. the TGA of a single sheet of the SR-3136. 
polyethylene chains respectively. The entire sample was almost evaporated before approaching to $500{ }^{\circ} \mathrm{C}$ due to the complete thermal degradation of polyethylene backbones. The results appear to be consistent with the previous polyethylene blends [17]. Figure S2 demonstrates the DSC results in which two peaks at $146.7^{\circ} \mathrm{C}$ and $401.8^{\circ} \mathrm{C}$ corresponding respectively to the melting point of the UHMW-PE and likely to be an exotherm due to the thermal decomposition of the polymers. The crystallization temperature was not observed since there is no residual left in the pan in the cooling process as shown in the TGA measurement. The melting point provided by the DSC data was also used to estimate the density of the sample and the degree of crystallization. Using the data provided in [18], the density and the degree of crystallization were interpolated to be $0.99 \mathrm{~g} / \mathrm{cm}^{3}$ and $68 \%$.

For overall elemental composition and structural analysis of the SR3136, the EDX and the XPS measurements were performed respectively. The EDX analysis of the SR-3136 gives that $87.6 \%$ of C from the UHMW$\mathrm{PE}$ and $3.0 \%$ of $\mathrm{O}, 2.9 \%$ of $\mathrm{Na}$ and $6.5 \%$ of $\mathrm{Cl}$ due to the resins utilized in the lamination process are considered to be present. The XPS measurements (Figure S3) were conducted within an area of $400 \mu \mathrm{m}$ spot size. Table S2 represents the peak table for the SR-3136. For C $1 \mathrm{~s}$, the peak was fitted using four major peaks appeared at binding energies of $284.7 \pm 0.2 \mathrm{eV}, 285.6 \pm 0.2 \mathrm{eV}, 286.6 \mathrm{eV}$ (fixed), $288 \mathrm{eV}$ (fixed). These four peaks can be assigned respectively to (i) $\mathrm{C}-\mathrm{C}$, (ii) $\beta$-COOR, (iii) $\mathrm{C}-\mathrm{N}$ or $\mathrm{C}: \mathrm{O}$ and (iv) $\left(\mathrm{CH}_{2}\right)_{\mathrm{n}}$ or C:O groups [19-23]. Thus, the first peak at $284.7 \pm 0.2 \mathrm{eV}$ seems to be from $\mathrm{sp}^{2}$ type carbon. The other three peaks at higher energies are due to bonds between carbon and oxygen and from $\left(\mathrm{CH}_{2}\right)_{\mathrm{n}}$. The results from the analysis of $\mathrm{O} 1 \mathrm{~s}$ peak further suggest the presence of oxides at the surface of the SR-3136.

\subsection{Ballistic studies}

The main functionality of fiber-reinforced composite ballistic armor is to absorb the kinetic energy of the projectile. The absorption of kinetic energy depends on the material properties like fabric pattern, volume density, and fiber surface characteristics. During the ballistic crashing, considerable heat was generated at the impact zone.

In today's technology, in order to test and evaluate the ballistic performance of armor plates against light weapons, standards of NIJ (National Institute of Justice) is taken as reference [24]. The reason for being taken these standards as a reference, today's threats of firearms such as a handgun, submachine gun, and infantry rifle are so similar to each other. Level III is used for body armor that is being fabricated against the impact of infantry riffle's bullet in today's modern army. Based on the NIJ standard, the maximum depth that occurs on the surface of a backing material, which is made by oil-based clay simulating human skin must be no deeper than $44 \mathrm{~mm}$ [3]. Therefore, ballistic tests were performed in accordance with NIJ STD 0103 standards. The armor plate was located $15 \mathrm{~m}$ away from the projectiles that were fired perpendicular to the target plane. Armor plate must satisfy the maximum back

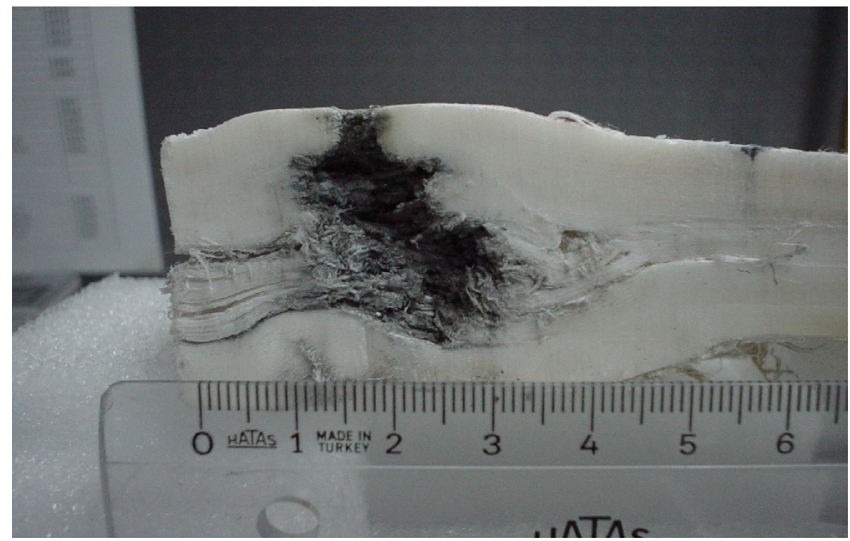

Fig. 4. Side view of armor plates after the ballistic test.

surface bulging of $44 \mathrm{~mm}$ under threat of a projectile. Each shot is at least $50 \mathrm{~mm}$ away from the edge of the armor plate and the minimum distance between shots on the plate is also $55 \mathrm{~mm}$. The test results for several gunshots were summarized in Table S4. The average velocity of the projectile was measured to be $849.2 \mathrm{~ms}^{-1}$. Fig. 4 demonstrates that the maximum back surface bulging was $32 \mathrm{~mm}$ which did not exceed the $44 \mathrm{~mm}$.

\subsection{Laser composite interaction}

Lasers can be operated in two different modes, namely continuous wave (CW) and pulsed beam. In the CW operation, constant power in time is emanated from the laser as a stream of photons. Therefore, the large amount of laser power accumulates heat on the target with no interruption. The laser beam causes a heat generation on the target through energy carriers including phonons or electrons and their collisions. When the laser strikes to the material, it might be scattered, absorbed or reflected with all different ratios depending on the energy density, wavelength, exposure time and material properties as well. If the Interaction between the laser and the material is mostly the absorption, then this process leads to heat generation and material removal with some mechanism. The electric field of the beam causes the structure of the material to vibrate which causes a heating effect and that leads to first melting, boiling, and evaporating finally drilled as a result of photo-thermal ablation. The maximum temperature is always reached at the center of the beam. CW lasers ablate through a thermodynamic process: localized heating of the target followed by phase change. In the experiment, the fabricated composite armor is located at $15 \mathrm{~m}$ away from the laser. Then, the laser radiation is focused on the sample. The schematic and the side view of the IR image of laser striking on the target are shown in Fig. 5A and B.

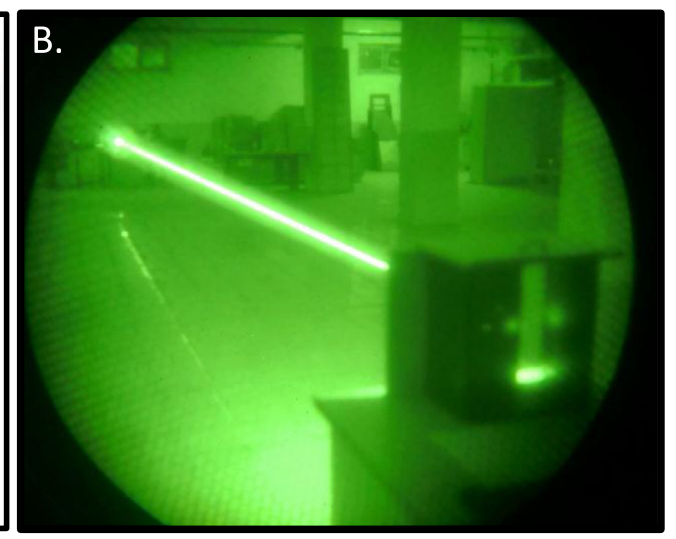

Fig. 5. A. Schematic and B. side view of IR camera image of laser striking on the target. 

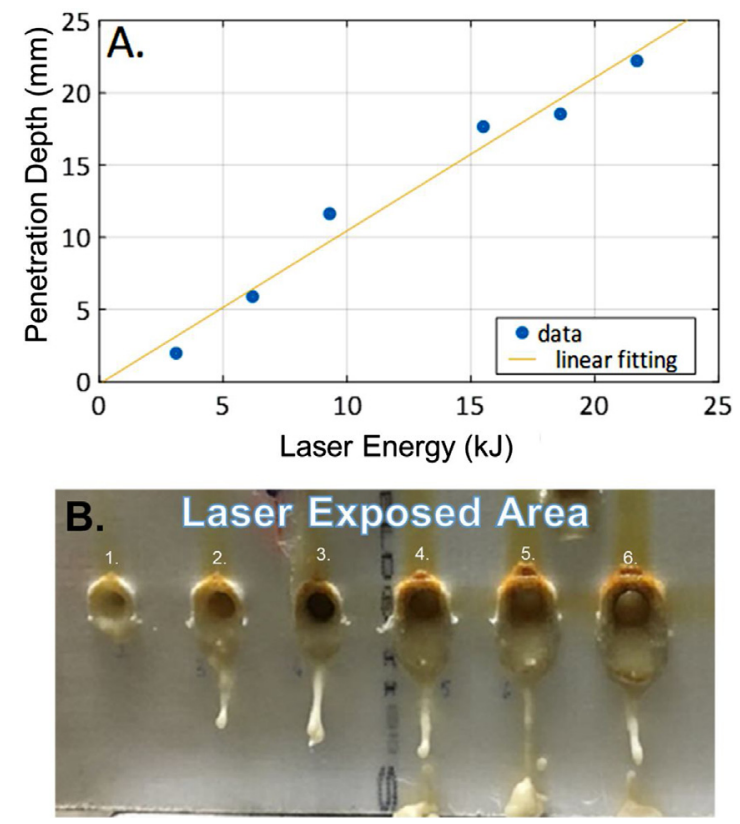

Fig. 6. A. The penetration depth vs the laser energy in kJ and B. the optical image of the drilling of ballistic composites by the laser from 1 to 6 . Material thickness is $22.2 \mathrm{~mm}$. Slight swelling is observed around the hole when the laser shines to the sample.

The penetration depth with respect to the laser energy is given in Fig. 6A. The corresponding optical image of the laser exposed area of the composites is given in Fig. 6B as well. Each laser exposed area in the image was formed due to the exposure to the laser light for different energy values. From left to right, the corresponding laser energy values were $2,6,11.8,17.8,18.6$, and $22.3 \mathrm{kJs}$ with the laser power of $155 \mathrm{~W}$. The laser-melted material can emit particles such as clusters and molecules which carry away the heat when leaving the material surface and this is shown just underneath of the drilling in Fig. 6B. In the ablation mechanisms, the boiling of the molten material phase and consequently melt expulsions, and ablation occur due to phase changes caused by thermal gradients which is not rapid. The temperature of the laser illuminated area recorded by the thermal camera reaches above $450{ }^{\circ} \mathrm{C}$ as shown in Fig. 7. These results are consistent with the TGA results (Fig. 2B) providing approximately 99.9 percent of the ablated target with a temperature above the onset value of $428.7^{\circ} \mathrm{C}$ would vanish after the melting and evaporation processes.

\subsection{Material physical properties upon laser irradiation}

The morphology and the microstructural analyses of the laser exposed SR-3136 (SR-3136-LE) were conducted using stereomicroscopy, scanning electron microscopy (SEM) and the XPS techniques. Fig. 8A. shows the surface of the SR-3136-LE by the stereomicroscope (Model: ZEISS AXIO). It can be clearly seen that the entry hole are relatively larger than the exit hole. The diameters of the entry and exit holes were $16.0 \mathrm{~mm}$ and $2.4 \mathrm{~mm}$ respectively. The shape of the drills can be considered to have an agreement with the laser keyhole mechanism [25] as a simple depiction is schematically represented in Fig. 8B. This also suggests that the high-power laser drilling of the composite material caused tapering that seems to have a small asymmetric behavior close by the entry hole on the side where the gravitational field was experienced. Therefore, the asymmetric tapering was considered to be due to the effect of the gravity on the upward motion of the molten material. Such an effect could be quite possible since more molten material appears to be deposited on the side where the asymmetric tapering is initiated. This was also shown in Fig. 6B when the slight swellings were observed from 1-6 in Fig. 6B.

Then, both the irradiated and not irradiated surfaces were investigated using the SEM studies. Fig. 9 represents the typical surface morphology of the area of (a) an unexposed (SR-3136 with 77 layers), (b) the laser exposed and (c) structural damage formed in an unexposed area. The red and white arrows show the direction of the laser irradiation suggesting the shock wave could create cracks in an unexposed area along the sample surface in the same direction of laser irradiation.

Furthermore, the elemental composition and the structural analysis of the SR-3136-LE were determined respectively using the EDX and the XPS measurements as well. The EDX analysis yields the SR-3136LE comprises of $74.5 \%$ of C, $12.6 \%$ of O, $5.3 \%$ of N, 3.3\% of K, $2.6 \%$ of $\mathrm{Na}$ and $1.7 \%$ of $\mathrm{Cl}$ in weight. Thus, the laser exposure resulted in rises in the relative amount of oxides and nitrides on the surface with respect to the SR-3136 (not exposed). Figure S5 shows the C $1 \mathrm{~s}$ and O $1 \mathrm{~s}$ spectra whose peak positions are given in Table S5. It is apparent from the XPS spectra for the sample that the highest peak intensity occurs at around $284.7 \mathrm{eV}$ (C $1 \mathrm{~s}$ ) and $532.8 \mathrm{eV}$ (O $1 \mathrm{~s}$ ). C $1 \mathrm{~s}$ peak was deconvoluted using four peaks located at $284.7 \pm 0.2 \mathrm{eV}, 286.3 \pm 0.2 \mathrm{eV}$, $286.5 \mathrm{eV} \pm 0.2,288.2 \mathrm{eV} \pm 0.2$. The peak at $284.7 \mathrm{eV}$ is $\mathrm{C}-\mathrm{C}$ bond (non-oxygenated $\mathrm{C}$ ). The $\mathrm{C} 1 \mathrm{~s}$ XPS spectrum has also three oxygen
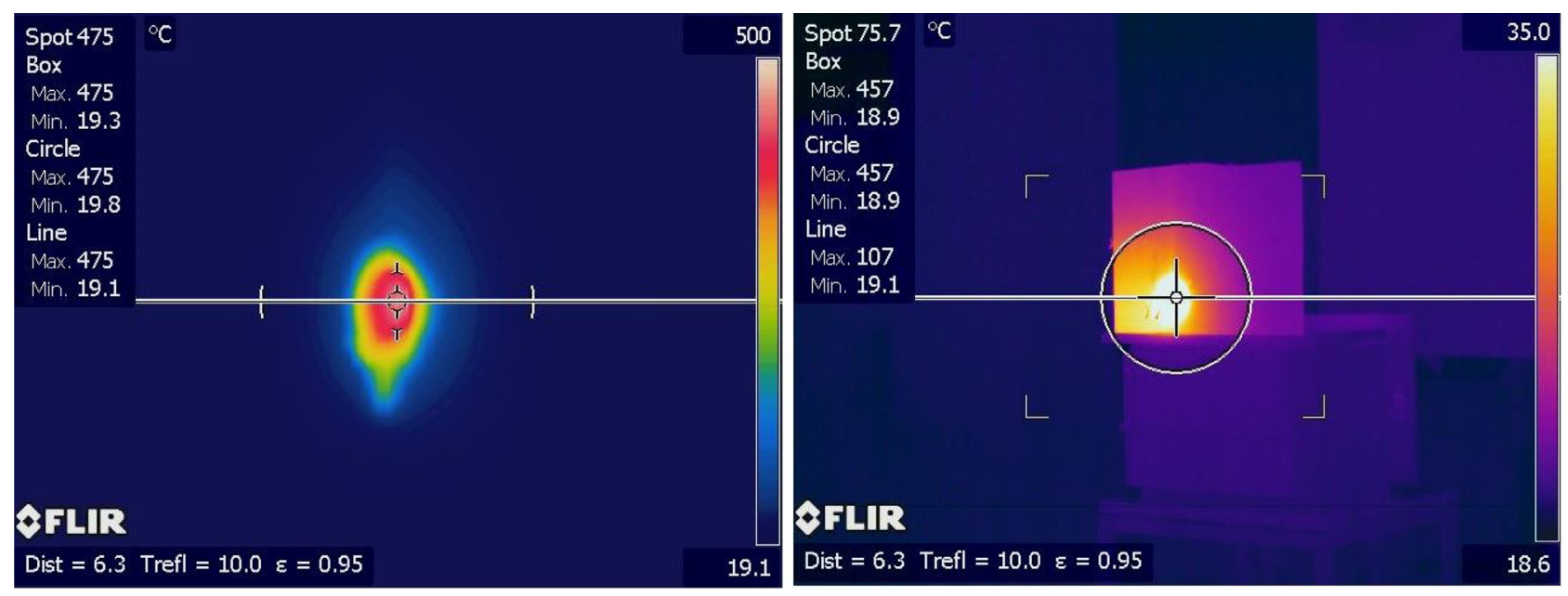

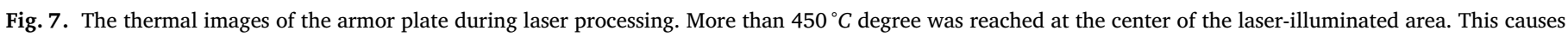
permanent damage through melting and evaporation. 

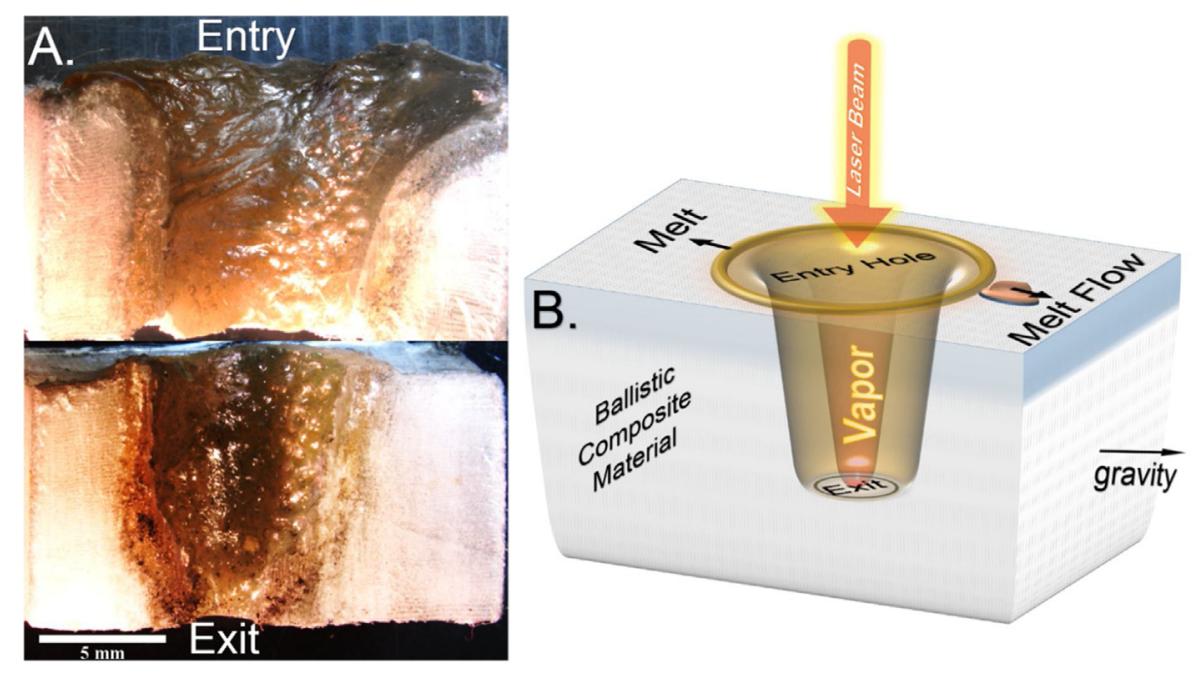

Fig. 8. A. The cross-sectional stereomicroscope image of the SR-3136-LE showing an asymmetric keyhole formation. The scale bar is $5 \mathrm{~mm}$. B. The schematic of the keyhole formation upon the laser exposure.
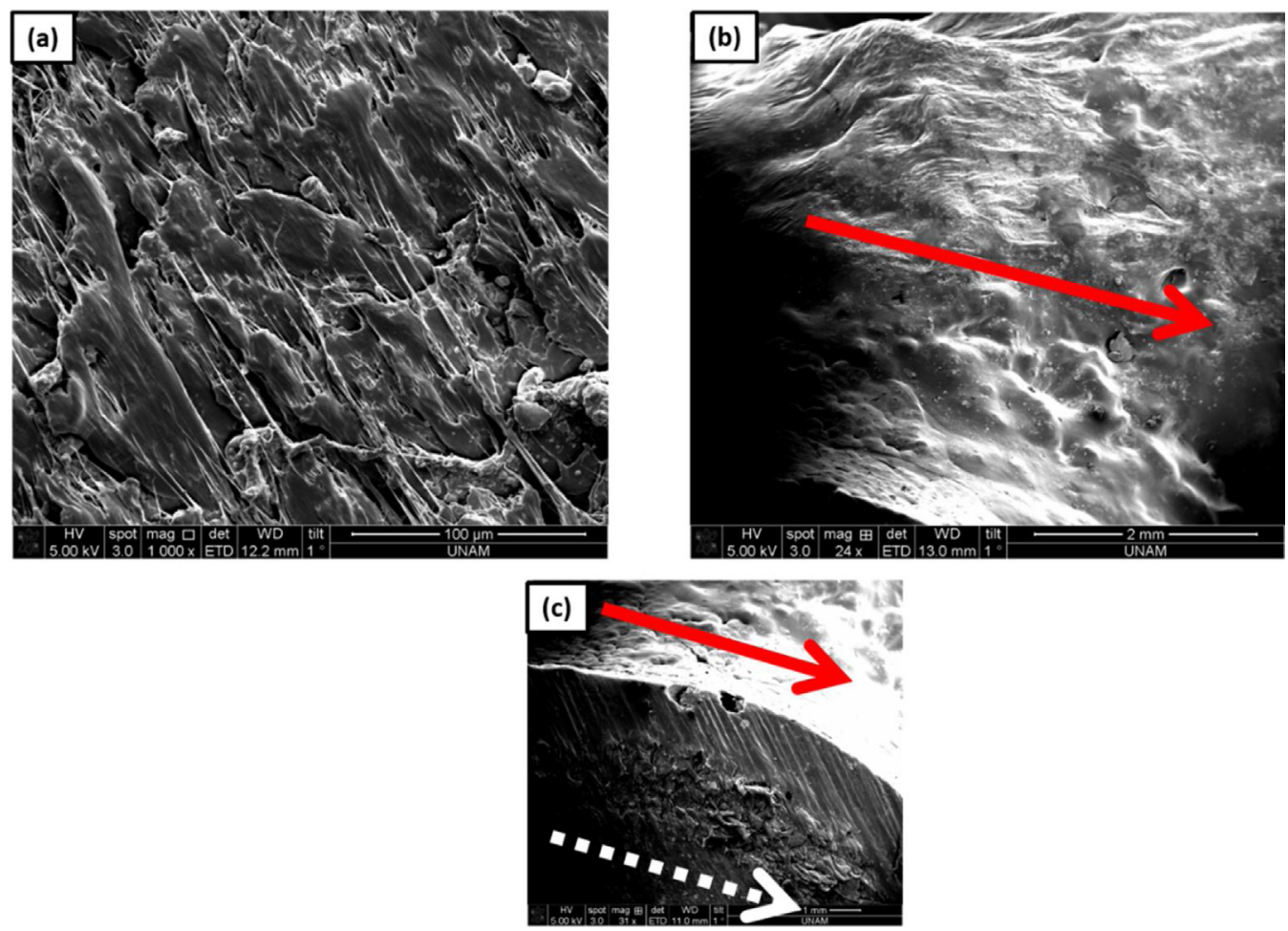

Fig. 9. The scanning electron microscopy micrographs of (a) the SR-3136 composite and (b,c) the SR-3136-LE In (c), the deformation formed by the shockwave of the laser irradiation is demonstrated.

functional groups [C-O at $286.3 \mathrm{eV}, \mathrm{C}-\mathrm{N}$ at $286.5 \mathrm{eV}$, the carbonyl $(>\mathrm{C}: \mathrm{O})$ at $288.2 \mathrm{eV}$ ). The results reveal that the structure of the SR-3136LE was evolved upon the laser irradiation. In addition, a small shoulder at $290.3 \mathrm{eV}$ can be considered to be due to p-p interaction bond. Furthermore, the $\mathrm{O} 1 \mathrm{~s}$ peak was determined to consist of three peaks at $530.6 \pm 0.2 \mathrm{eV}, 532.1 \pm 0.2 \mathrm{eV}, 532.8 \mathrm{eV}$ (fixed) referring to three oxygen peaks arising from O:N-C (530.6 eV), C:O (carbonyl $532.1 \mathrm{eV}$ ) and OAC:O $(532.8 \mathrm{eV})$ groups. Overall, when compared to the SR-3136, SR3136-LE was found to comprise three different bonds including $\mathrm{C}-\mathrm{N}$, $\mathrm{C}: \mathrm{O}$ and $\mathrm{O}: \mathrm{N}-\mathrm{C}$.

\section{Conclusion}

A first study on the interaction between a high-power laser and a ballistic composite of the SR-3136 was demonstrated together with the conventional ballistic tests. The armor material is extremely absorptive at $915 \mathrm{~nm}$ and would not be protective in its current form when such NIR laser weapons are in use and targeting the material within $\mathrm{kJ}$ of laser energy regimes. The entry and exit holes were observed to have different sizes resulting in tapering upon drilling of the armor material which is consistent with keyhole formation mechanism. The material surface next to the hole was shown to have cracks due to the shock wave created by the absorption of the high-power laser. The laser-exposed surface has an increase in the contents of the oxides and nitrides with respect to the unexposed surface. The results give insights on the effect of a high-power laser hitting a ballistic composite material and possible damages, however, the diode lasers used in this study can have an expansion of the beam shape when increasing the laser current and at long distance operations. Therefore, high-power lasers with a more quality of the beam profile such as high-power fiber lasers could still have a lethal 
effect even from relatively the long distances (few kilometers) for the conventional ballistic composites.

\section{Acknowledgments}

The authors acknowledge the financial support provided by Republic of Turkey, The Ministry of National Defense, 5th Main Maintenance Factory Directorate under the fund of Latas-100-High-power Laser Plotter Development Project. The authors also thank both Gazi University Electro-optic Research Laboratory and I. D. Bilkent University-UNAM for the infrastructural supports.

\section{Supplementary materials}

Supplementary material associated with this article can be found, in the online version, at doi:10.1016/j.optlaseng.2019.03.016.

\section{References}

[1] Chen X. Introduction. In: Chen X, editor. Adv. Fibrous Compos. Mater. Ballist.. Woodhead Publishing; 2016. p. 1-10.

[2] Yang $Y$, Chen X. Investigation of failure modes and influence on ballistic performance of Ultra-High Molecular Weight Polyethylene (UHMWPE) uni-directional laminate for hybrid design. Compos Struct 2017;174:233-43. doi:10.1016/j.compstruct.2017.04.033.

[3] Chen X, Chu Y. Failure mechanisms and engineering of ballistic materials. In: Chen X, editor. Adv. Fibrous Compos. Mater. Ballist.. Woodhead Publishing; 2016. p. 263-304.

[4] Tresansky A.C. Numerical modeling of high irradiance electromagnetic beam effects on composite and polymer materials. 2013.

[5] Boley CD, Rubenchik AM. Modeling of laser interactions with composite materials. Appl Opt 2013;52:3329. doi:10.1364/AO.52.003329.

[6] Li M, Li S, Yang X, Zhang Y, Liang Z. Effect of lay-up configuration and processing parameters on surface quality during fiber laser cutting of CFRP laminates. Int J Adv Manuf Technol 2018. doi:10.1007/s00170-018-2728-9.

[7] Greiner S, Wudy K, Wörz A, Drummer D. Thermographic investigation of laserinduced temperature fields in selective laser beam melting of polymers. Opt Laser Technol 2019;109:569-76. doi:10.1016/j.optlastec.2018.08.010.

[8] Ashok J, Varaprasad PLH, Birch JR. Handb. Opt. Constants solids. Elsevier; 1997. p. 957-87. doi:10.1016/B978-012544415-6.50089-3.
[9] Lacroix F, Allheily V, Diener K, Eichhorn A, Gillet M, L'Hostis G. Thermomechanical behavior of aeronautic structural carbon epoxy composite submitted to a laser irradiation. Compos Struct 2016;143:220-9. doi:10.1016/j.compstruct.2016.02.009.

[10] Sing SL, Yeong WY, Wiria FE, Tay BY, Zhao Z, Zhao L, et al. Direct selective laser sintering and melting of ceramics: a review. Rapid Prototyp J 2017;23:611-23. doi:10.1108/RPJ-11-2015-0178.

[11] Williams E, Lavery N. Laser processing of bulk metallic glass: a review. J Mater Process Technol 2017;247:73-91. doi:10.1016/j.jmatprotec.2017.03.034.

[12] Malesa M, Kujawińska M, Kustron K, Siedlecki K. Investigations of high power laser beam interaction with composite materials by means of digital image correlation and thermography. In: Titterton DH, Ackermann H, Bohn WL, editors. High-Power lasers Technol. Syst. Platforms, eff.. SPIE; 2017. p. 19. doi:10.1117/12.2281119.

[13] Liang Y, Liu P, Xiao J, Li H, Wang C, Yang G. A microfibre assembly of an iron-carbon composite with giant magnetisation. Sci Rep 2013;3:3051. doi:10.1038/srep03051.

[14] Carr DJ, Crawford CM. Fabrics and composites for ballistic protection. In: Chen X, editor. Adv. Fibrous Compos. Mater. Ballist.. Woodhead Publishing; 2016. p. 109-19.

[15] Zhang D, Sun Y, Chen L, Zhang S, Pan N. Influence of fabric structure and thickness on the ballistic impact behavior of Ultrahigh molecular weight polyethylene composite laminate. Mater Des 2014;54:315-22. doi:10.1016/j.matdes.2013.08.074.

[16] Tauc J. Optical properties and electronic structure of amorphous Ge and Si. Mater Res Bull 1968;3:37-46. doi:10.1016/0025-5408(68)90023-8.

[17] Contat-Rodrigo L, Ribes-Greus A, Imrie CT. Thermal analysis of high-density polyethylene and low-density polyethylene with enhanced biodegradability. J Appl Polym Sci 2002;86:764-72. doi:10.1002/app.10974.

[18] Hitachi High-tech Coor. DSC measurement of polypropylene. 1986.

[19] Wang K, Li J, Wang S. The surface modification of a polyethylene (PE) film using an air Coplanar barrier discharge plasma at atmosphere pressure. In: 2nd Int. Conf. Electron. Mech. Eng. Inf. Technol.; 2012. p. 1038-42.

[20] Chappell PJC, Brown JR, George GA, Willis HA. Surface modification of extended chain polyethylene fibres to improve adhesion to epoxy and unsaturated polyester resins. Surf Interface Anal 1991;17:143-50. doi:10.1002/sia.740170305.

[21] Yang J, Yan X, Chen J, Ma H, Sun D, Xue Q. Comparison between metal ion and polyelectrolyte functionalization for electrophoretic deposition of graphene nanosheet films. RSC Adv 2012;2:9665. doi:10.1039/c2ra20948a.

[22] Choi DM, Park CK, Cho K, Park CE. Adhesion improvement of epoxy resin/polyethylene joints by plasma treatment of polyethylene. Polymer (Guildf) 1997;38:6243-9. doi:10.1016/S0032-3861(97)00175-4.

[23] López GP, Castner DG, Ratner BD. XPS O $1 \mathrm{~s}$ binding energies for polymers containing hydroxyl, ether, ketone and ester groups. Surf Interface Anal 1991;17:267-72. doi:10.1002/sia.740170508.

[24] Department of Justice U, of Justice Programs O, Institute of Justice N. Ballistic Resistance of Body Armor NIJ Standard-0101.06. Washington, DC 20531: 2008.

[25] Cho JH, Na SJ. Theoretical analysis of keyhole dynamics in polarized laser drilling. J Phys D Appl Phys 2007;40:7638-47. doi:10.1088/0022-3727/40/24/007. 